\title{
EU-medlem och Rysslands granne: En analys av Finlands strategiska kultur
}

\author{
Av Hanna Smith^
}

The European Centre of Excellence for Countering Hybrid Threats och Aleksanteri Institute, University of Helsinki

\begin{abstract}
EU Member and Russia's Neighbor: An Analysis of Finland's Strategic Culture

This article begins by examining strategic culture studies, in particular Alan Bloomfield's concept of different sub-cultures in strategic culture. It then focuses on the border between Russia and Finland and how Finnish EU membership was made possible by Finland's decision not to challenge the WWII border treaty with the Soviet Union after the Soviet collapse. Next, it investigates the debates and public opinion relating to Finland's 1994 EU referendum, to see how the dynamics changed three strategic cultural sub-groups: "selfdefence", "Westernisers" (including Western international organizations) and "Reassurance and Dialogue with Russia". In conclusion, it is argued that EU membership altered the hierarchy of these strategic culture sub-groups in Finland, as well as their substance. These changes were, however, more evolutionary than revolutionary.
\end{abstract}

Key words: Finland, Russia, European Union, strategic culture, subgroups

Finlands grannskap med det betydligt större Ryssland har lett till att förhållandet till Ryssland tydligt präglats av olika hotbilder. De med täta intervall förskjutna gränserna mellan Finland och Ryssland, till följd av olika krig, har bidragit till styrkan hos dessa hotbilder. Fastän Rysslands närvaro alltid har överskuggat formuleringen av den finska utrikespolitiken har Rysslands förhållandet förblivit relativt stabilt. Sedan Finlands självständighet år 1917 är det den västliga dimensionen av utrikespolitiken, som utvecklats mest och som i dag spelar en betydande roll i den finska utrikespolitikens utformning.

Den västliga dimensionen har förändrats mest drastiskt sedan slutet av det kalla kriget och Finlands anslutning till den Europeiska unionen. Ändock, bakom denna förändringsprocess finns det en viss kontinuitet i det finska utrikespolitiska tankesättet, vilket denna artikel undersöker och förklarar med hjälp av begreppet strategisk kultur. Medan det finns en underliggande kontinuitet är det fortfarande så att Finland måste svara på föränderliga internationella lägen.

^Kontaktinformasjon: Hanna Smith. Email: hanna.smith@hybrdicoe.fi 
Artikelns huvudargument är att Finlands medlemskap i den Europeiska unionen ändrade kontexten för formuleringen och verkställandet av Finlands utrikespolitik. Detta är en viktig aspekt vid förklaringen av Finlands reaktioner på de senaste kriserna gällande Ryssland, särskilt Rysslands annektering av Krim och interventionen i östra Ukraina. EU-medlemskapet har gjort det svårare att inta en strikt neutral hållning. Som följd har karaktären och vikten av argument gällande en nyckelfråga $i$ den finska utrikespolitiken - Natomedlemskapet - också ändrats.

Genom begreppet strategisk kultur demonstrerar denna artikel att detta dock inte har inneburit en fundamental förändring av det finska utrikespolitiska tankesättet. Det har snarare betytt ett skifte i balansen mellan grupper som stödjer olika aspekter av den strategiska kulturen. Genom Alan Bloomfields (2012) omdefiniering av strategisk kultur analyseras dessa skiften i denna artikel enligt en modell för strategisk kultur, som innehåller konkurrerande underkulturer. Bloomfield ser konceptet strategisk kultur som ett omtvistat begrepp, men likväl nyttigt då man strävar efter att kartlägga ett lands utrikes- och säkerhetspolitiska beteende. Han introducerar ett nytt element i studierna av strategisk kultur, vilket enligt honom övervinner de två huvudproblem, som kritikerna av strategisk kultur har identifierat: att modellerna för strategisk kultur är för koherenta och därmed har svårigheter att förklara avvikelser från modellen; och att modellerna innehar för stor kontinuitet, vilket gör det omöjligt att förklara och ta hänsyn till långfristiga förändringar i den strategiska kulturen. Det centrala i modellen är idén att

the proposed model of co-existing, competing sub-cultures envisages various domestic groups like political parties, ethnic groups or institutions promoting their favoured subculture - with a particular cultural interpretation of whom their state's friends and foes are at its core - as the best way of defining and solving the various strategic challenges and opportunities their state faces (Bloomfield 2012: 438).

Finlands medlemskap i den Europeiska unionen förändrade hierarkin bland dessa undergrupper samt även deras innehåll. Detta hade för sin del även en inverkan på förhållandet mellan Finland och Ryssland. Den finsk-ryska gränsen undersöks här som ett väsentligt element vid utformandet av den finska strategiska kulturen. Den finsk-ryska gränsens historia har därmed spelat en central roll vid utformandet av Finlands strategiska kultur.

Artikeln börjar med att närmare betrakta studier i strategisk kultur och följer Bloomfields föreställning. Tre undergrupper i den finska strategiska kulturen under kalla kriget är definierade; "självförsvar och neutralitet", "tillit och dialog» och "västanhängare». Sedan undersöker artikeln den finsk-ryska gränsen och hur Finlands EU-medlemskap möjliggiordes av Finlands beslut att inte utmana gränsavtalet med Sovjetunionen från det andra världskriget efter att Sovjetunionen upplöstes.

Därefter granskar artikeln debatter och allmänna åsikter gällande Finlands EU-folkomröstning för att illustrera hur dynamiken mellan de kulturella undergrupperna i Finlands strategiska kultur förändrades, vilket skapade de nutida undergrupperna "självförsvar", "västanhängare» (inklusive västerländska internationella 
organisationer) och "tillit och dialog med Ryssland». Dessa grupper motsvarar de positioner som framlagts av Finlands president Sauli Niinistö. Slutligen studerar artikeln hur den nya positionen gentemot Ryssland tolkas av dessa undergrupper.

Som slutsats argumenteras att Finlands EU-medlemskap först förändrade de strategiska kulturernas hierarki, varefter det även förändrade dessa gruppers innehåll. Förändringarna var dock framförallt evolutionära snarare än revolutionära.

\section{Den strategiska kulturens undergrupper och Finland}

Teorin om strategisk kultur är omtvistad och dess analytiska värde har ifrågasatts (Johnston 1995). Som respons till de kritiska analyserna har nya skrifter uppstått till försvar för vad Johnston kallade den första generationens strategiska kultur (Gray 1999, 2007). Sedan dess har diskussionen om strategisk kultur generellt cirkulerat kring Johnston-Gray-debatten (Bloomfield 2 012). S om L antis (2009) har pekat ut är "argument om kulturellt inflytande på strategi grundade i klassiska verk om distinkta nationella maner». Vad Lantis kallar klassiska verk är detsamma som Johnstons första generation av strategisk kulturanalys (Gray 1981; Weigley 1960; Snyder 1977). Lantis framhäver både potentialen och problemen vid användandet av strategisk kultur som ett begrepp, som belyser politiska inblickar (Lantis 2009).

Den första generationens strategiska kulturanalys använde begreppet mer eller mindre enligt Jack Snyders definition:

the sum total of ideals, conditional emotional responses, and patterns of habitual behaviour that members of the national strategic community have acquired through instruction or imitation and share with each other with regard to [nuclear] strategy (Snyder 1977: 8).

Ann Swindler (1986) har påpekat att från en sociologisk synvinkel ligger den strategiska kulturens vikt inte vid att definiera handlingarnas slutsats, utan vid att utstaka de kulturella komponenter som används för att skapa handlingsstrategier.

Enligt Kerry Longhurst (2000) bildas den strategiska kulturen genom formativa upplevelser och den kan förändras, antingen fundamentalt eller bit för bit, vid kritiska moment i kollektivets upplevelser. Longhursts synpunkt besvarar särskilt Johnstons kritik om hur den första generationens strategiska kulturrepresentanter framställde ett alltför koherent och deterministiskt betraktelsesätt genom deras användning av begreppet. Trots den högljudda kritiken är de som skrivit om strategisk kultur eniga om att begreppet kan ha ett visst värde »om det används varsamt, som ett sätt att organisera vår kunskap om de ämnen vi kan påstå oss veta ett och annat om» (Haglund 2011).

Alan Bloomfield (2012) har konstaterat att det är dags att gå vidare från JohnstonGray debatten. Han utvecklade en modell som behandlade strategisk kultur som en enhet, som innehåller ett flertal samtidigt förekommande underkulturer. Var och en av dessa underkulturer framställer en olik tolkning av statens internationella sociala/ 
kulturella kontext - det vil säga vem som är statens vänner och ovänner och hur de materiella variablerna, som är relevanta för strategiskt beslutsfattande, sedan tolkas i en särskild kontext - geografi, relativ makt, teknologisk utveckling och så vidare (Bloomfield 2012). Bloomfield framhäver att undergrupperna "existerar i föränderliga dominans-, underordnande- och bundenhetsförhållanden, som hänför sig till varandra» (Bloomfield 2012: 452). Detta förhållande mellan grupperna kan förklara förändringarna i ett specifikt lands utrikespolitik, även om vissa bakomliggande drag uppehålls.

Två punkter i Bloomfields tolkning i förhållande till underkulturer är särskilt viktiga: historiska hotbilder spelar en betydande roll i den strategiska beslutsfattandeprocessen då det gäller att välja vem man litar på och vem man fruktar (Bloomfield 2012: 452); och de olika strategiska kulturella undergrupperna använder sig av en blandning mellan sociala/kulturella och materiella/tekniska faktorer för att konkurrera med varandra om att erbjuda den "riktigaste» tolkningen av statens internationella kontext (Bloomfield 2012: 453). Enligt Bloomfield kan man "samla ledtrådar om de olika underkulturernas framgång genom att fästa uppmärksamhet på debatter om vilken internationell roll staten borde spela, vad den är eller vad den borde vara $i$ omvärlden» (Bloomfield 2012: 453).

I Finlands fall är det möjligt att identifiera tre olika undergrupper. De har var och en sina egna undergrupper, som har uppstått som ett resultat av den föränderliga internationella miljön. Dessa tre undergrupper kan konstrueras runt Arto Nokkalas (2016: 80) tre element i Finlands utrikes- och säkerhetspolitik under det kalla kriget. Fastän Nokkala hänvisar till olika dimensioner i utrikespolitiken motsvarar de rakt av Bloomfields ide om strategiska underkulturer. Här heter de grupperna "självförsvar och neutralitet", "tillit och dialog» och "västanhängare».

Först härskade den dominerande undergruppen som starkt betonade självförsvar, både militärt och på hela samhällets nivå. Denna grupp såg Finland i mycket som en isolerad aktör mellan öst och väst. För denna grupp framstod neutralitetspolitiken som den bästa lösningen. Inom dessa ramar var den roll som Finland kunde tillägna sig i internationell politik den neutrala statens roll. Den identitet som passade Finland var identiteten hos en stat mellan öst och väst, en roll som i lika grad uttryckte varsamhet och en aning misstro gentemot öst (Sovjetunionen) och mot väst (Förenta staterna).

Den andra gruppen gynnade en politik baserad på tillit och dialog med Sovjetunionen. Även om Finlands utrikes- och säkerhetspolitik under det kalla kriget var officiellt neutral, vilket placerade Finland utanför både det östra och västra blocket, ledde det finsk-ryska förhållandet i praktiken till Finlands internationella image som en stat som lutade mot öst. Innan det andra världskriget placerades Finland som ett "västerländskt» land i geopolitisk litteratur, men efter kriget positionerades Finland ofta i östra Europa (Paasi 1999: 671).Vissa analyser har hävdat att Finlands säkerhetspolitik, sammankopplad med landets utrikespolitik, har fölit Rysslands styrkor och svagheter (Apunen 2003). 
Denna analys kan även associeras med den andra gruppen, eftersom relationerna mellan Finland och Ryssland spelar huvudrollen i dess inställning. Även om Ryssland var i huvudfokus och dess viktigaste determinant för den andra gruppen uteslöt detta inte andra dimensioner. Om Ryssland har varit svagt har Finland strävat efter att skapa multilaterala förhållanden, med kraftig vinkling åt väst, liksom under mellankrigstiden och återigen under 1990-talet. Och när Ryssland varit kraftfullt har Finland strävat efter att uppehålla bilateralism med Ryssland, ibland även på bekostnad av sin egen suveränitet, såsom under det kalla kriget (Apunen 2003).

Mellan självständighetsförklaringen år 1917 och utbrottet av det andra världskriget letade Finland efter en ram i vilken landet kunde placera sig inom den internationella ordningen. Detta leder oss till den tredje undergruppen: den grupp som aktivt söker aktiva förbindelser med västvärlden. Under mellankrigstiden var denna grupp synlig och dominant, men i efterkrigskontexten blev den undanskjuten till tredje plats. Detta antyder inte att gruppen inte skulle ha varit aktiv, men den försökte bedriva Finlands västpolitik under Sovjetradarn tillsammans med de andra grupperna.

Hiski Haukkala (2012) har presenterat tre olika linjer, som även kan betraktas som den strategiska kulturens undergrupper, på motsvarande sätt som i Nokkalas analys om kalla kriget. Enligt Haukkala var de två mest dominerande grupperna "småstatsrealism" bredvid en stormakt (Ryssland) och den liberala linjen (även kallad euroatlantism) som betonar internationell rätt samt strävar att förankra sig mot väst (Haukkala 2012: 85-86; se även Heikka 2005). Dessa två linjer liknar Nokkalas grupper "tillit och dialog» och "västanhängare». Till dessa två linjer har Haukkala och Vaahtoranta (2016: 54) lagt till en tredje dimension - globalism - som strävar efter att minska maktpolitikens roll eller stormaktspolitik i internationella relationer och istället förstärka normernas, reglernas och institutionernas värld i en global skala.

Denna tredje dimension liknar för sin del på många vis det kalla krigets grupp "självförsvar». Under det kalla kriget föreställde självförsvarsgruppen för Finland sig en identitet mellan öst och väst och strävade internationellt efter neutralitet i sin säkerhetspolitik, dock med betydande tonvikt på självförsvar. Samtidigt försökte den driva en utrikespolitik som främjade förstärkandet av internationell lag och idéer om kollektiv säkerhet.

Man kan se dessa tre element i konflikt med varandra eller som kompletterande, beroende på den synvinkel man väljer att inta. Dessutom står det en fritt att debattera om dessa grupper någonsin konkurrerade om den dominanta positionen. Detta är kopplat till uppfattningen om vänner och ovänner i Finlands utrikes- och säkerhetspolitik. Officiellt betraktar Finlands utrikes- och säkerhetspolitik Ryssland som en osäkerhetskälla snarare än ett uttalat hot (Forsberg 1999: 113). Detta innebar att olika utrikespolitiska linjer kunde drivas samtidigt. Om man dock undersöker den finsk-ryska gränsens historia blir det uppenbart att ur en historisk synvinkel har gränsen framkallat en dominant uppfattning om Ryssland som en ovän, vilket har haft en inverkan på alla strategiska undergrupper i Finland. 


\section{Den finsk-ryska gränsen som källa till finska hotbilder}

Den nutida gränsen mellan Finland och Ryssland har förskjutits många gånger under historiens lopp. Gränsen har flyttats fram och tillbaka under århundraden, ibland ökande det "finska" området mot öster, ibland ledde skeendena till en reträtt mot väster. Många av slagen mellan Sverige och Ryssland har tagit plats på finsk mark. Plundringståg i finska byar från det östra hållet har levt vidare i populärhistorien. Enligt Anssi Paasi skapas gränsernas betydelse i centren (Paasi 199: 670). På så sätt har politiska beslut gällande gränsen och den roll gränsen har spelat i Finlands historia och beslutsfattande blivit en politisk konstruktion, men de bidrar även till den strategiska kulturens kontext. Gränser, uppfattade på detta vis, handlar i grund och botten om hotbilder.

År 1323 undertecknade Sverige och Novgorod ett betydande gränsavtal, Nöteborgstraktaten. År 1595 slöts freden i Teusina mellan Sverige och Moskvariket; freden i Stolbova mellan Sverige och Ryssland år 1617; freden i Nystad år 1712; och freden i Åbo år 1743. Vart och ett av dessa traktat ändrade gränsen mellan den finska delen av Sverige och Novgorod/Moskvariket/Ryssland. Alla undertecknades efter ett krig. På så vis blev gränsen i stor utsträckning en markör för krig och fred. Som Laitinen har argumenterad, Finlands östra gränshistoria är en bra demonstration om att det rått tider då säkerhetsfrågornas status och intensitet har varierat betydligt (Laitinen 2003: 24).

En gränsändring har varit särskilt betydande, eftersom den ledde till skapandet av en ny slags identitet för Finland. Under många århundraden var "ovännen» kejsardömet Ryssland - Finlands "härskare». Då måste den västeuropeiska ramen, det vill säga den gamla "vännen» Sverige och dess allierade, anta »ovännens» roll. Denna förändring utgör en extern "chock» för omgivningen, så som Berger har beskrivit det i sin analys om strategisk kultur (Berger 1998: 9). Dessa chocker kan leda till förändringar i en stats identitet. I detta fall hade Finland inte varit ett självständigt land som sådant, men det hade utvecklats som en särskild nationell entitet redan under det svenska väldet.

Det var också den tidpunkt då strategiska underkulturer uppstod: de som lutade åt väst, de som lutade åt öst, och de som strävade efter att skapa en särskild finländsk identitet mellan öst och väst. Efter freden i Fredrikshamn, som ställde Finland under det ryska kejsardömets välde år 1812, försköts gränsen återigen, tillbaka till gränsen innan år 1721, men nu betecknade den en intern gräns inom det ryska riket. Detta innebar att det finska territoriet expanderade på nytt. Den fungerade även som grunden för fredsfördraget i Tartu år 1920, vilket bekräftade den gräns som Finland, nu självständigt sedan år 1917, skulle behålla ända till det andra världskriget, då Finlands territorium återigen krympte efter överlåtandet av landområden till Sovjetunionen.

Här kan man känna igen intressanta paralleller till de nuvarande problemen gällande gränser mellan Ryssland och Ukraina. Så länge Ukraina eller Finland låg inom det ryska eller sovjetiska riket var de ryska/sovjetiska makthavarna betydligt mera 
generösa när det gällde gränsfrågor. Men, när dessa områden sökte uppnå självständighet ändrades tolkningen av gränserna, vilket ledde till en ökad konfliktrisk mellan dessa länder och Ryssland. I både det finska och det ukrainska fallet realiserades denna konfliktpotential i form av krig.

Historien kring Finlands östra gräns har spelat en betydande roll i utformningen av Finlands uppfattningar gällande »ovänner». Den första chock som påverkade Finlands national- och statsidentitet var kriget åren 1808-1809, då Finland blev en del av kejsardömet Ryssland. Den andra chocken var självständigheten år 1917, den tredje det andra världskriget och den fjärde var Sovjetunionens kollaps. Varje gång skedde det en förändring som berörde gränsen mellan Finland och Ryssland.

Under Sovjettiden var gränsen mellan Finland och Ryssland den längsta gränsen mellan en västerländsk kapitalistisk stat och den socialistiska stormakten. Gränsen var ett exempel på en ideologiskt stängd gräns. I de finsk-ryska relationerna kunde den historiska gränsflytten återigen ha utvecklats till ett problem efter Sovjetunionens kollaps. Det var tidpunkten för Tysklands enande och de baltiska ländernas självständighet, som båda upphävde det andra världskrigets resultat. Det fanns en del hopp och önskan på båda sidorna av den finsk-ryska gränsen om att gränsen skulle ha justerats på nytt. Förståeligt väckte dessa förhoppningar och önskningar oro i Moskva. Officiellt tog Finland aldrig upp saken. Ett nytt grannskapsavtal undertecknat av Finland och Ryssland år 1992 fastställde den finsk-ryska gränsen enligt definitionen i Parisfreden år 1947 (Joenniemi 1998: 191).

Eftersom den strategiska kulturens miljö även kan begränsa en stats strategiska möjligheter till dem som anses vara »kulturellt tillgängliga», särskilt då det gäller relationer med andra stater, satte Finlands nya bekräftelse av Parisfreden från år 1947 en slutpunkt för en betydande historisk faktor - östgränsen som ett skiftande koncept - och därmed begränsades Finlands strategiska möjligheter. Joenniemi (1998: 193) hävdar att "Finlands tolkning av EU-logiken har varit att gränsen bör vara stabil och inte ett föremål för konflikt». Den östra gränsen och frekventa förskjutningar av den införde en stark hotbild av Ryssland i Finlands utrikes- och säkerhetspolitik, vilken blev en av de ledande linjerna i alla undergrupper inom Finlands strategiska kultur.

Därmed innebar Sovjetunionens upplösning mycket mera för Finland än bara att en ideologisk motståndare försvann. Den möjliggjorde även förstärkandet av den "västliga dimensionen» i Finlands utrikes- och säkerhetspolitik samt skapade en möjlighet att omdefiniera Ryssland som »vän» i stället för »ovän». Detta gjordes genom att nedklassa och omtolka frågan om Karelen. I detta hade varje undergrupp - självförsvar, tillit och dialog samt västanhängarna - samma mål, dock av olika orsaker. När alla tre grupper hade samma intressen var det lätt att enas om hur man skulle närma sig frågan. Forsberg (1996: 443) har noterat hur »Finlands motvillighet att ta upp gränsfrågan kan förklaras genom synsättet att det inte var vist att provocera Ryssland, samt genom behovet av att signalera stabilitet till den Europeiska unionen». 
Dessa synpunkter är en del av de olika undergruppernas uppfattning om situationen efter Sovjetunionens kollaps och de ligger i linje med Finlands strategiska kultur. Fastän situationen stöddes av alla tre grupper gynnade beslutet framförallt dem som orienterat sig västerut, eftersom det öppnade möjligheten att ställa Finland på västvärldens sida i form av Finlands EU-medlemskap och att samtidigt förändra Finlands förhållande till Ryssland.

\section{Finlands medlemskap i den Europeiska unionen: En triumf för västanhängarnas undergrupp?}

När Sovjetunionen kollapsade uppstod det en möjlighet för integrering med "västliga» länder. Detta utmanade den finska strategiska kulturens kontext, som hade existerat under flera årtionden. Den neutralitetsstatus som Finland hade tillägnat sig under det kalla kriget började bli allt svårare att upprätthålla efter att den gamla världsordningen försvann. Den hade också varit en svår position att uppehålla redan under det kalla kriget. Neutraliteten utmanades särskilt inom de områden av Finlands utrikesoch säkerhetspolitik som strävade efter att skapa kontakter med Västeuropa. Finlands politiska profil betonade västerländska demokratiska värden, och ett särskilt betydande element var integrationsprocessen i Norden.

Ytterligare hade Finlands väg mot ett djupare samarbete med västeuropeiska länder inletts redan under 1960-talet, då Finland blev en associerad medlem i den Europeiska frihandelssammanslutningen (EFTA). År 1974 undertecknade Finland ett frihandelsavtal med den Europeiska ekonomiska gemenskapen (EEG). EES (Det europeiska ekonomiska samarbetsområdet)-förhandlingarna mellan EEG och EFTA banade vägen för rätt så smidiga EU-medlemsförhandlingar, eftersom grundarbetet redan hade gjorts under EES-förhandlingarna. Alla dessa processer förflyttade Finland ständigt i riktning mot Västeuropa, alltmedan den dominerande undergruppen fortfarande var självförsvar och neutralitet.

Den strategiska kulturens kontext mellan öst och väst, en stark uppfattning om Finlands position i den internationella miljön, i vilken självförsvar och neutralitet var den förhärskande principen, påverkade den allmänna åsikten om vilka internationella organisationer, unioner och allianser Finland skulle delta i och vilka deras risker och fördelar var (Bäck 2017: 26). Tanken om att söka medlemskap i den Europeiska unionen var snarare frågan om en evolution än en revolution, även om Sovjetunionens kollaps skapade ett tillfälle till något som ännu år 1989 uppfattades som en avlägsen möjlighet.

Under det kalla kriget var argumenten för integration fast kopplade till Finlands behov gällande ekonomi och handel, men i och med Sovjetunionens kollaps övertog säkerhetsargumenten den dominerande rollen (Forsberg \& Vaahtoranta 2001: 71). Som Finlands förra president Mauno Koivisto konstaterade: "de starkaste grunderna för att ansöka om EU-medlemskap tycks för mig ligga inom säkerhetspolitiken» (Koivisto 1997: 246). Gränsfrågan var en 
säkerhetspolitisk fråga, som har haft en inverkan på Finlands utrikespolitik och dynamiken mellan de olika undergrupperna.

Det slutliga resultatet från Finlands EU-folkomröstning i oktober 1994 visade att 57 procent stödde medlemskapet och 43 procent ställde sig emot det (Pesonen 1994: 41-51). Finland var rätt tudelat innan folkomröstningen. Efter folkomröstningen har frågan om EU-medlemskapet dock inte varit en splittrande fråga i Finland i högre grad jämfört med till exempel de andra nordiska länderna (Raunio \& Saari 2017: 21). Det var betydande för den strategiska kulturens undergrupper, eftersom de var mer eller mindre eniga gällande gränsfrågan, men detta var inte längre fallet då det handlade om Finlands EU-medlemskap.

Enligt Finlands Gallup stödde över 60 procent av finländarna EU-medlemskapet år 1990 medan bara 10 procent ställde sig emot detta. 30 procent hade inte bestämt sig. I stort sett kunde man fördela dessa andelar mellan undergrupperna så att de 10 procenten representerar undergruppen tillits- och dialogpolitik med Sovjetunionen. De 30 procent som inte hade bestämt sig representerade närmast dem som betonade självförsvar och neutralitet, och de som gynnade medlemskapet var västanhängarna tillsammans med en del av gruppen som förordade självförsvar och neutralitet.

När Finlands president, regering och riksdag fattade beslutet att ansöka om EU-medlemskap år 1992 hade andelen som motsatte sig ökat till över 30 procent. Nivån för stöd och motstånd i medlemskapsfrågan varierade frekvent. Antalet som ställde sig negativa till medlemskapet överskred dem som stödde medlemskapet i början av hösten 1993. När Finland undertecknade medlemskapsavtalet i juni 1994 var stödet för medlemskapet nästan 50 procent och motståndarnas andel cirka 30 procent. I augusti 1994, innan folkomröstningen i oktober, var lägren för och mot jämställda vid nivån 40 procent. Man har sagt att Nej-rörelsen i Finland för övrigt hänvisade till den nationella självständigheten, medan Ja-gruppen betonade internationellt samarbete (Jahn \& Storsved 1995: 33). På så sätt kan man tolka, i linje med Bloomfields kategorier, att det i Finland faktiskt fanns olika undergrupper, som betraktade Finlands strategiska val på olika sätt.

Med EU-medlemskapet, vilket för övrigt betraktas som en seger för västanhängarnas undergrupp, kom även andra viktiga frågor som utmanade balansen mellan undergrupperna och samtidigt även vissa betydande aspekter i Finlands strategiska kultur. Undergruppen för självförsvar och neutralitet, som placerade Finland som ett land mellan öst och väst, förblev stark. Den påverkade Finlands utrikespolitik mera än västanhängarna, även om den senare tog hem segern i frågan om EU-medlemskapet och hade gått förbi undergruppen för tillit och dialog i undergruppernas hierarki. Neutralitetsbegreppet blev omöjligt att använda i kontexten för medlemskapet i den Europeiska unionen. Finland var allierat med den Europeiska unionen och hade fattat ett tydligt beslut om att ställa sig mera till väst än till öst. Konceptet förblev dock viktigt för Finland. Neutraliteten var ett viktigt verktyg för Finlands utrikespolitik. Den var ett särskilt förhållningssätt för staten. På många sätt blev neutralitetsbegreppet, som existerade som en dominant diskurs i Finlands utrikespolitik under cirka 
45 år, kopplat till den nationella identiteten, vilket gjorde det svårt för Finland att avvika från konceptet (Ojanen 2016).

Man har noterat att förändringar i neutralitetens definitioner och praxis har främjats av nationella eliter, ofta i motsats till den allmänna opinionen (Löden 2012: 272). Detta gällde även Finland. Under hösten 1993, ett år innan folkomröstningen, visade en gallup ordnad av Näringslivets Delegation (EVA) att 80 procent av finländarna ansåg det viktigt att bevara Finlands neutralitet. Finlands förra utrikesminister och centerpartiets tidigare ordförande Paavo Väyrynen uppgav till och med att "Finland kan förbli neutralt i den Europeiska unionen" (Arter 1995: 370). Från hösten 1992 strävade den finska politiska eliten att omdefiniera den säkerhetspolitiska agendan genom att formulera neutralitetens kärna som militär alliansfrihet kombinerad med ett trovärdigt nationellt försvar (Arter 1995: 372). Denna formulering fungerar som en god illustration av alla tre undergruppernas påverkan på den. Västanhängarna fick EU-medlemskapet, gruppen för självförsvar och neutralitet uppehöll den starka tonvikten på självförsvar, medan de som strävade efter tillit och dialog med Ryssland skulle acceptera militär alliansfrihet.

EU-medlemskapet innebar en historisk förändring i Finlands förhållande till Ryssland, eftersom beslutet fattades $i$ en strävan efter att integrera landet med "väst», i detta fall EU. Hiski Haukkala har hävdat att EU-medlemskapet förvandlade Finlands historiska "triangel för tilltro» - Sankt Petersburg, Berlin och Stockholm - till Moskva, Bryssel och Washington (Haukkala 2012: 85-86), vilket tyder på att Finland hade tillägnat sig en fullkomligt ny slags säkerhetsram. Detta och den förändrade säkerhetsmiljön innebar naturligtvis strider mellan de olika strategiska undergrupperna i Finlands politik.

Västanhängarna nådde visserligen en mera dominant ställning i undergruppernas hierarki, men sist och slutligen nådde man ändå inte en hegemonisk position. Dessutom utvecklades västanhängarnas undergrupp till två skilda riktningar: de som lade all tonvikt på den Europeiska unionen, och de som såg EU som bara en del av projektet för Finlands västanhängare. Självförsvarsgruppen hade några gemensamma drag med den senare, men måste överge neutralitetsbegreppet i sin strävan efter att uppehålla sin position gällande ett "trovärdigt självförsvar». Gruppen för tillit och dialog med Ryssland måste för sin del ta den Europeiska unionens gemensamma ställning i beaktan, vilket gjorde samarbete och avtal på bilateral basis svårare.

\section{Finlands anpassade strategiska kultur och Ryssland efter EU-medlemskapet}

Genom EU-medlemskapet genomgick Finlands sätt att betrakta sig själv inom internationell politik en betydande förändring. Statens självbild inom internationell politik är en viktig faktor i strategisk kultur i enlighet med Bloomfields definition. Den andra viktiga faktorn var definitionen av vänner och ovänner. Denna faktor har möjligen förändrats mindre genom EU-medlemskapet än vad man har antagit. Den sista delen 
av artikeln studerar förändringarna i Finlands förhållande med Ryssland sedan Finlands EU-medlemskap genom de fyra hörnpelare av Finlands nuvarande utrikespolitik enligt Finlands president Sauli Niinistös tolkning. De fyra hörnpelare är även kopplade till den strategiska kulturens tre olika undergrupper inom Finlands utrikes- och säkerhetspolitik. President Niinistö har förklarat Finlands nuvarande utrikespolitik genom att ha följande fyra principer: Ett trovärdigt självförsvar; integration med väst; Ryssland; och internationell ordning - framförallt normativa ramar så som internationell lag (i den ordningen) (Niinistö 2015).

Den första gruppen, självförsvar och neutralitet, som placerade Finland mellan öst och väst, måste anpassa sin ställning, eftersom neutralitetsbegreppet förlorade sin relevans genom Finlands EU-medlemskap. Gruppen måste även tona ner idén om Finland mellan öst och väst och placerade i stället Finland tydligt inom de västerländska ramarna. De geopolitiska realiteterna var dock fortfarande närvarande, så som gränsen mellan Finland och Ryssland samt grannskapet mellan en liten stat och en stormakt. För denna grupp var, och är fortfarande, militära frågor viktiga.

Sovjetunionens kollaps förändrade naturligtvis hotbilden från det kalla krigets tid. Ur Natos eller de västerländska stormakternas synvinkel var den ryska militären inte i gott skick. Men, ur en liten grannessynvinkel var mängden av de materiella och mänskliga tillgångar som Ryssland hade till förfogande även under 1990talet som basis för en ny nationell militärkraft imponerande. Dessutom skilde sig Finlands dåvarande perspektiv även från den bredare bilden gällande uppskattandet av Rysslands militära kapacitet. Därför hastade Finland inte med att ändra sina självförsvarsprioriteringar.

Ett tecken på att något höll på att förändras, om än långsammare än i många andra länder, var dock det faktum att år 2011 var Finland den sista av EU-staterna att underteckna Ottawafördraget, som förhindrade användning av landminor. Den nationella debatten i Finland gällande användning av minor är fortfarande livlig. Strax innan riksdagsvalen år 2015 krävde Jussi Niinistö, dåvarande chef för försvarsutskottet och Finlands nuvarande försvarsminister, att minorna återställs och lät förstå att inte bara hans eget parti, sannfinländarna, utan även vissa medlemmar i samlingspartiet stödde upphävandet av minförbudet (Matikainen 2015).

Debatten innan Finland undertecknade Ottawafördraget återspeglade även de olika undergrupperna. Dåvarande president Tarja Halonen, utrikesministern och flera organisationer specialiserade på fredsforskning stödde avtalets undertecknande, medan försvarsministern ställde sig emot det. Debatten kring landminorna speglade skillnader inom undergrupperna: mellan dem som önskade bevara alla traditionella självförsvarselement och dem som strävade efter en stark integration med den västliga legala sfären, samt dem som betraktade tillit och dialog som kärnan i Finlands Rysslandspolitik. Debatten framhävde även det faktum att om minst två undergrupper har liknande intressen kan de utmana den dominanta undergruppen.

Även om det i Finland, liksom i de flesta EU-medlemsstaterna, fanns en trend att avlägsna sig från det kalla krigets militära tonvikter, fortsatte Finland dock att betona 
militär kapacitet. Även om Finland begränsade sin vapenkraft från nivån under det kalla kriget och undertecknade Ottawafördraget uppehöll Finland allmän värnplikt och det så kallade omfattande säkerhetstänkandet, vilket innebar att samhällets alla områden var koordinerade i en strävan efter att skapa nationell motståndskraft. Detta leder till slutsatsen att även om självförsvarsgruppen utmanades flera gånger inom Finland, samt befann sig i disharmoni med internationella trender, så uppehöll den en stark position.

Finlands EU-medlemskap föranledde ett nytt slags argument relaterat till säkerhet samt framkallade en omstrukturering av säkerhetstänkandet från kalla krigets tid. Det ändrade dock inte självförsvarsgruppens dominanta ställning. Efter Rysslands annektering av Krim år 2014 och kriget i Donetsbäckenet förstärkte gruppen ytterligare sin ställning. Detta återspeglade sig även i rangordningen av Finlands olika utrikespolitiska trender i president Niinistös tal. Allt detta tydde på att det läge, där Ryssland spelade en ledande roll i Finlands strategiska kultur, och därmed även vid beslutsfattandet, inte hade förändrats markant även om balansen hade ändrats så att den avspeglade förändringarna i den internationella politiska miljön.

I hierarkin för undergrupperna i Finlands strategiska kultur drog västanhängarnas grupp nytta av Sovjetunionens kollaps och Finlands EU-medlemskap. Hanna Ojanen har demonstrerat hur "EU-medlemskapet blev ett centralt element i Finlands säkerhetspolitik tillsammans med militär alliansfrihet och ett självständigt försvar» (Ojanen 2000: 5). Den finska debatten och den allmänna opinionen innan Finlands EU-folkomröstning framhävde skillnaden mellan de olika undergrupperna, som framhävts ovan. Fastän EU-medlemskapet har lett till en utveckling mot väst $i$ Finlands utrikes- och säkerhetspolitik och den västliga dimensionen har blivit mycket mera dominant jämfört med dess ställning under det kalla kriget har debatten mellan västanhängarnas grupp och gruppen för tillit och dialog förblivit livlig.

Den största förändringen för Finlands Rysslandspolitik har varit EUmedlemskapet. Medlemskapet gjorde det möjligt för Finland att hävda att Finland är och förblir en del av väst (Niinistö 2015). Under Finlands 25 år som EU-medlemsstat har det pågått en oavbruten debatt om förhållandet med Ryssland borde hanteras bilateralt eller multilateralt genom EU-strukturerna. Centerpartiets ordförande och nuvarande premiärminister Juha Sipilä har stött sig på alla olika undergrupper då han talat om Finlands utrikespolitik. Han har sagt att Finland står fast i EU-lägret, men strävar efter att uppehålla den bilaterala dialogen med Ryssland, medan han samtidigt betonar självförsvarets kontinuerliga vikt (PR 136/2014).

Dessa kommentarer yttrade Sipilä under en debatt i Finlands riksdag (PR 136/2014), och de fungerar som en god illustration av skillnaderna mellan bilateralism och multilateralism i Finlands och Rysslands förhållande. Skillnaderna visar sig i betoningar, även om debatten cirkulerar kring de tre olika dimensionerna. Ibland sammanfaller de med partigränserna, ibland inte. Förutom debatten i januari 2014 är debatten i mars 2014 (PR 23/2014) ett bra exempel. Marsdebatten framhävde återigen hur vissa, till exempel premiärminister Jyrki Katainen, betonade att Finlands 
politik gentemot Ryssland var en del av EU:s Rysslandspolitik och att Finland med andra ord närmade sig Ryssland från ett EU-perspektiv. Den efterföljande premiärministern Alexander Stubb tillägnade sig stort sätt samma linje följande år (PR 136/2014).

Vissa riksdagsledamöter, så som Erkki Tuomioja, har betonat hur även andra ramar än EU är viktiga för Finlands och Rysslands förhållande, och nämnde till exempel Organisationen för säkerhet och samarbete i Europa (OSSE) som det viktigaste ramverket för att handskas med Ryssland i kontexten av Ukrainakrisen. Även Timo Soini, Finlands nuvarande utrikesminister, betonade i båda debatterna hur aktuell arbetspraxis i Finlands och Rysslands förhållande har baserat sig på bilateralism (PR 23/2014; PR 136/2014). I dessa två debatter poängterade de flesta talarna den finsk-ryska gränsen. Att gränsen regelmässigt tas upp i debatterna bevisar hur den långa gränsen alltfortfarande framkallar hotbilder, även om gränsen, som Tuomioja påpekade, är den mest fridfulla gränsen i den Ryska federationen (PR 23/2014). De två debatterna illustrerar olika betoningar för undergrupperna i Finlands strategiska kultur i diskussioner om Ryssland och även om själva EU.

EU-medlemskapet har också framkallat en ny slags realism i Finlands utrikespolitiska identitet, även om det fortfarande finns rum för tillit och dialog - småstatsrealism som Haukkala och Vaahtoranta (2016) kallar det - i det kalla krigets stil. Som EU-medlem är Finland en del av gemenskapen, och försöket att isolera sig ifrån den har sina gränser. Finlands position gällande EU-sanktionerna mot Ryssland, i vilket fall Finland känner sig förpliktigat att stödja EU:s position, är ett bra exempel på detta (Haukkala \& Vaahtoranta 2016: 61).

EU-medlemskapet har fört med sig en oemotsäglig västlig och europeisk dimension till Finlands utrikes- och säkerhetspolitik, som ibland hade svårigheter med att passa in dimensionen för tillit och dialog. Christopher Browning (2000: 50) har hävdat att "den västanghängare berättelsen", som ger Finland en västligt skapad identitet, "ofta tycks verka rätt besvärlig vid sidan av den kontinuerliga officiella utrikespolitiken för alliansfrihet». Somliga har även hävdat att Finland med sin betoning på EU och förhandlingar med Ryssland har gått miste om gynnsamma tillfällen genom EU:s policy, vilket har försämrat förhållandet mellan Finland och Ryssland (RytövuoriApunen 2007).

Debatten gällande balansen mellan den Rysslandspolitik som drivs av Finland genom EU och den finsk-ryska bilaterala dialogen tog fart genom Ukrainakrisen som började år 2014. Det tyder även på att säkerhetsfrågor alltfortfarande spelar en betydande roll i Finlands utrikes- och säkerhetspolitik. Självförsvarsgruppens dominanta position kommer därmed knappast att försvagas.

Den ökande oron för säkerheten har även fått västanhängarnas grupp att skärpa sina argument att Finland inte har varit integrerat nog i den västra sfären, eftersom landet har allierat sig endast politiskt men inte militärt. Detta är kopplat till den pågående debatten om Finlands Natomedlemskap, vilket faller utanför ramarna för denna artikel. Från dessa debatter kan man dra följande slutsatser: För det första 
framkallade EU-medlemskapet en helt ny dimension i Finlands Rysslandspolitik i och med att Finland driver sin Rysslandspolitik genom EU. För det andra är säkerhetsfrågor fortfarande ett betydande inslag i Finland gällande Ryssland, vilket är en orsak till varför självförsvarsgruppens upprätthåller en ledande position i hierarkin bland undergrupperna i den strategiska kulturen. För det tredje fortsätter gruppen för tillit och dialog med Ryssland att påverka Finlands utrikes- och säkerhetspolitik och, även om de är underordnade västanhängarnas ramverk, kommer de att fortsätta att bromsa upp deras strävan efter närmare militärt samarbete.

\section{Slutsatser}

Begreppet den strategiska kulturen har blivit kritiserat, och Johnston-Gray debatten har kastat en skugga över begreppets användning. Alan Bloomfield (2012) introducerade ett nytt sätt att närma sig den strategiska kulturens begrepp, genom att han föreslog att det förfinas genom att studera olika undergrupper. Bloomfield hävdade att användningen av begreppet strategisk kultur på så sätt skulle undvika de problem den tidigare hade mött, det vill säga kritik om att den strategiska kulturen betraktas som alltför koherent och deterministisk utan en möjlighet för förändring, samt invändningen att den strategiska kulturen fastnar för mycket i kontinuitet.

I denna artikel har jag tagit upp Bloomfields ramar för den strategiska kulturens undergrupper och tillämpat dem i en analys av Finlands utrikes- och säkerhetspolitik. Debatterna inom Finlands samhälleliga och politiska strukturer speglar väl klassifikationerna för dessa tre undergrupper, vilket gör Bloomfields modell allt trovärdigare. De tre undergrupperna som studerades var självförsvar och neutralitet, västanhängarna samt tillit och dialog. Ryssland har spelat, och spelar fortfarande, en mycket dominant roll för alla tre undergrupper. I Bloomfields modell är det viktigt att skilja åt vem som betraktas som landets vänner och ovänner och hur landet positionerar sig på den internationella politiska arenan. I det finländska fallet har historien och den långa gränsen med Ryssland haft en stark påverkan på hur de olika undergrupperna formulerar sina argument. Hotbilderna gällande Ryssland förblir starka.

Sovjetunionens kollaps var en stor chock för det internationella systemet. För Finland föranledde det en möjlighet att omdefiniera sin position i den internationella politiska ordningen. Finland valde medlemskapet i den Europeiska unionen för att bryta med positionen "mellan öst och väst». Detta hade inte varit möjligt utan Finlands beslut att bekräfta den gräns som definierades i Parisfreden år 1947. Genom att röja undan alla spekulationer gällande gränsen mellan Finland och Ryssland omdefinierade Finland även sig själv in i den västra sfären, så att Finlands president Sauli Niinistö år 2015 kunde hävda att »Finland var och är ett västerländskt land». Debatten innan Finlands EU-folkomröstning visade tydligt de olika undergruppernas preferenser och argument. Den visade även att när minst två undergruppers intressen möts uppstår det en möjlighet att skapa en ändring i den strategiska 
kulturen. Finlands medlemskap i den Europeiska unionen år 1994 föranledde en förändring i Finlands strategiska kultur.

För självförsvarsgruppen betydde EU-medlemskapet att de måste ge upp neutralitetsbegreppet, men de förblev likväl i topp i undergruppernas hierarki eftersom politisk omorientering inte avskaffade säkerhetsfrågorna.

Ukrainakrisen år 2014 och senare Donald Trumps tillträde som Förenta staternas president år 2017 har förorsakat ett ytterligare skifte i balansen mellan undergrupperna. Den mera hotfulla bilden av Ryssland och det opålitliga partnerskapet med Förenta staterna har förstärkt självförsvarsgruppens position genom att betona hur den internationella politiska miljön ur Finlands synvinkel betraktas som ytterst instabil, samt att vänner och ovänner inte är lätt definierade.

Finlands respons på EU-sanktionerna mot Ryssland $i$ följd av Ukrainainterventionen kan betraktas som en kompromiss mellan de olika undergrupperna: som EU-medlem kände sig Finland förpliktat att delta i sanktionerna, men man signalerade dock starkt att man var obekväma med principerna bakom dem. Finland förstärkte även sitt militära samarbete med Nato och de andra Nordiska länderna, medan landet återigen bekräftade sitt engagemang i nationell värnplikt och ett omfattande säkerhetstänkande.

Samtidigt har Finland för det mesta lyckats fortsätta samarbetet med Ryssland i lokala frågor, och de diplomatiska relationerna på hög nivå är fortfarande starka. Västanhängarna lyckades alltså förhindra en öppen klyfta mellan Finland och EU, självförsvarsgruppen behöll sitt inflytande över kärnan i Finlands säkerhetstänkande, och gruppen för tillit och dialog fortsatte att påverka diplomatiska relationer.

Västanhängarnas undergrupp, som i början vann terräng inom undergruppernas hierarki, stötte på problem när det gällde Finlands förhållande med Ryssland år 2014. Debatten om hur Finland borde koppla EU:s Rysslandspolitik med Finlands mera traditionella, bilaterala Rysslandspolitik förblir livlig i Finland, liksom den har varit under hela den tid Finland har varit medlem i EU. Västanhängarna för även en intern diskussion kring frågan om politisk samordning med väst är tillräckligt eller om Finland även borde ingå i en militär allians innan landet faktiskt kan identifiera sig själv som ett västerländskt land.

De som står mest i opposition till debatten är de som stöder tillits- och dialogpolitiken, traditionen och även de som för övrigt är kritiska gentemot en omorientering. I sin argumentation har gruppen för tillit och dialog också tillägnat sig bredare ramar än bara Finlands och Rysslands förhållande. De vill inte se Finland ställt mot Ryssland i öst-västdikotomin, utan stöder snarare större, internationella ramar i relation till internationell lag och internationella organisationer som OSSE och FN. För denne gruppen är säkerhetsfrågorna lika väsentliga som för de andra undergrupperna, men deras hantering av frågorna skiljer sig från de andras.

På så vis förändrades både undergruppernas substans samt balansen mellan grupperna genom Sovjetunionens kollaps och framförallt genom Finlands EU-medlemskap. Ett nytt skifte skedde i Ukrainakrisens spår år 2014. Dessa 


\section{EN ANALYS AV FINLANDS STRATEGISKA KULTUR | 102}

förändringar kan snarare betraktas som en evolutionär utveckling av den strategiska kulturen än en revolutionär avvikelse från den. Samtidigt visar analysen av undergrupperna i Finlands strategiska kultur att utrikes- och säkerhetspolitiken har starka låsningar till historien och särskilt till säkerhetsfrågor kopplade till det förflutna. Detta leder till att förändringar i den strategiska kulturen är långsamma, men inte omöjliga.

\section{Litteratur}

Apunen, Osmo (2003) "Continuity and change in Finnish-Russian relations» i Unto Vesa (red.) Maailman tutkimisesta ja muuttamisesta: juhlakirja Fyrki Käkösen täyttäessä 60 vuotta 23.1.2003. Tammerfors: Tapri (189-202).

Arter, David (1995) "The EU referendum in Finland on 16 October 1994: A vote for the West, not for Maastricht». Fournal of Common Market Studies 33 (3): 361-387.

Berger, Thomas U. (1998) Cultures of Antimilitarism: National Security Policy in Germany and fapan. Baltimore: Johns Hopkins University Press.

Bloomfield, Alan (2012) "Time to move on: Reconceptualizing the strategic culture debate». Contemporary Security Policy 30 (3): 437-461.

Browning, Christopher S. (2002) „Coming home or moving home? 'Westernizing' narratives in Finnish foreign policy and the reinterpretation of past identities». Conflict and Cooperation 37 (1): 47-72.

Forsberg, Tuomas (1996) "Explaining territorial disputes: From power politics to normative reasons". Fournal of Peace Research 33 (4): 433-449.

Forsberg, Tuomas (1999) »Between neutrality and membership: Finland's and Sweden's place in the NATO family" i NATO 50 Mapping the Future. The Washington Summit 23-25 April 1999. London: Agenda Publishing Limited (112-114).

Forsberg, Tuomas \& Tapani Vaahtoranta (2001) "Inside the EU, outside NATO: Paradoxes of Finland's and Sweden's post-neutrality». European Security 10 (1): 68-93.

Gray, Colin (1981) "National styles in strategy: The American example». International Security 6 (2): 21-47.

Gray, Colin S. (1999) "Strategic culture as context: The first generation of theory strikes back». Review of International Studies 25 (1): 49-69.

Gray, Colin S. (2007) "Out of the wilderness: Prime time for strategic culture». Comparative Strategy 26 (1): $1-20$.

Haglund, David G. (2011) "Let's call the whole thing off? Security culture as strategic culture». Contemporary Security Policy 32 (3): 494-516.

Haukkala, Hiski (2012) Suomen muuttuvat koordinaatit. Helsinki: Gummerus.

Haukkala, Hiski \& Tapani Vaahtoranta (2016) "Suomen turvallisuuspolitiikan linjat ja koulukunnat" i Fred Blomberg (red.) Suomen turvallisuuspoliittisen ratkaisun lähtökohtia. Helsingfors: Försvarshögskolan $(55-76)$.

Heikka, Henrikki (2005) "Republican realism: Finnish strategic culture in historical perspective». Cooperation and Conflict 40 (1): 91-119.

Jahn, Detlef \& Ann-Sofie Storsved (1995) "Legitimacy through referendum? The nearly successful dominostartegy of the EU referendums in Austria, Finland, Sweden and Norway». West European Politics 18 (4): 18-37.

Joenniemi, Pertti (1998) "The Karelian question. On the transformation of a border question". Conflict and Cooperation 33 (2): 183-206.

Johnston, Alastair Iain (1995) "Thinking about strategic culture». International Security 19 (4): 32-64.

Koivisto, Mauno (1997) Witness to History. The Memoirs of Mauno Koivosto, President of Finland, $1982-1994$. London: Hurst.

Laitinen, Kari (2003) "Geopolitics of the Northern dimension: A critical view on security borders». Geopolitics 8 (1): $20-44$.

Lantis, Jeffrey (2009) "Strategic culture and tailored deterrence: Bridging the gap between theory and practice». Contemporary Security Policy 30 (3): 467-485.

Löden, Hans (2012) "Reaching a vanishing point? Reflections on the future of neutrality norms in Sweden and Finland». Cooperation and Conflict (2): 271-284.

Longhurst, Kerry (2000) "The concept of strategic culture» i Gerhard Kummel \& Andreas D. Prufert (red.) Military Sociology: The Richness of a Discipline. Baden-Baden: Nomos (301-310). 
Matikainen, Matti (2015) "Niinistö: Jalkaväkimiinat saatava takaisin». Suomen Uutiset 13.2.2015. Tillgänglig på https://www.suomenuutiset.fi/niinisto-maamiinat-saatava-takaisin/. Läst 16.2.2018.

Niinistö, Sauli (2015) "Republikens president Sauli Niinistös nyårstal 1.1.2015». Tillgänglig på http://www. presidentti.fi/public/default.aspx?contentid $=319059 \&$ nodeid $=44810 \&$ contentlan $=3 \&$ culture $=$ sv-FI. Läst 16.2.2018.

Nokkala, Arto (2016) „Suomen puolustuspolitiikan käännekohtia» i Fred Blomberg (red.) Suomen turvallisuuspoliittisen ratkaisun lähtökohtia, Helsingfors: Försvarshögskolan (77-108).

Ojanen, Hanna (2000) Participation and Influence: Finland, Sweden and the Post-Amsterdam Development of the CFSP. Occasional Papers 11. Paris: Institute for Security Studies, Western European Union.

Ojanen, Hanna (2016) "Ruotsin ulko-, turvallisuus- ja puolustuspolitiikka» i Fred Blomberg (red.) Suomen turvallisuuspoliittisen ratkaisun lähtökohtia. Helsingfors: Försvarshögskolan (131-166).

Paasi, Anssi (1999) „Boundaries as social practice and discourse:The Finnish-Russian border». Regional Studies 33 (7): 669-680.

Pesonen, Pertti (red.) (1994) Suomen EU-kansanäänestys 1994. Raportti äänestäjien kannanotoista. Helsingfors: Europainformationen.

PR (23/2014), Plenarprotokoll 12.3.2014, "Statsministerns upplysning om EU-toppmötet och situationen i Ukraina». Finlands riksdag. Tillgänglig på https:/www.eduskunta.fi/SV/Vaski/Sidor/trip.aspx?triptype=rik sdagshandlingar\&docid=pr+23/2014. Läst 16.2.2018.

PR (136/2014), Plenarprotokoll 14.1.2015, "Aktuell debatt om relationerna mellan Finland och Ryssland», Finlands riksdag. Tillgänglig på https://www.eduskunta.fi/SV/vaski/Sidor/trip.aspx?triptype=riksdagshand lingar\&docid $=$ pr+136/2014. Läst 16.2.2018

Raunio, Tapio \& Juho Saari (red.) (2017), Reunalla vai ytimessä? Helsingfors: Gaudeamus.

Rytövuori-Apunen, Helena (2007) Unionin ajan idänpolitiikkaa. Helsingfors: Edita.

Snyder, Jack (1977) The Soviet Strategic Culture: Implications for Nuclear Options. Santa Monica: RAND Corporation.

Swindler, Ann (1986) "Culture in action: Symbols and strategies». American Sociological Review 51 (2): $273-286$. Vilkuna, Kustaa H. J. (2006) Paholaisen sota. Helsingfors: Teos.

Weigley, Russell F. (1960) The American Way of War. Bloomington: Indiana University Press. 